\title{
The Silent Suffering of Jane Doe: Negligence of Mental Health Problems in Daily Practice
}

Julius Kremling. ${ }^{\prime}$

\section{The Experience}

About the Author: Julius Kremling is a fourth year medical student who has studied in Germany, Ireland and Belgium.
Submission: May 9, 2014 Acceptance: Jun 28, 2014
In a vast number of different specialities and in primary care during placements, I have encountered many different diseases, patients and doctors. But one seems to be a constant visitor: Jane Doe. Jane Doe is no real patient but a synthesis of many I have seen in this form very often and who shows some distinct features that distinguishes her from other patients. It might be her first visit to this service or a review appointment, however, whatever it is, lots of investigations have been done or will be undertaken. When she enters the room the doctor focuses on her (physical) symptoms and signs, takes her history and examines her. While doing so, she usually breaks into tears repeatedly and mentions troubles in college or at her workplace, anorexia, insomnia, financial difficulties... the list seems to be endless. The attending doctor, however, only offers a few kind words and ignores the emotional and mental breakdown of the patient. Later, when the consultant reviews the patient, the whole lot repeats itself and again the mental status of the patient is ignored. She is reassured that she will be well looked after and receives a review appointment and maybe even a specialist consult. Her urgent need for psychotherapy or any kind of psycho-social support, however, is once again ignored.

I have chosen her name deliberately since we all know the unknown corpse that appears frequently on television. A corpse, not a human being, missed by nobody that only gets the attention it deserves once dead. Though this patient showed several features of depression, her presenting complaint was reduced to a pure physical problem while her chief complaint was ignored. Considering that, according to the Global Burden of Disease 2010 study, depressive disorders are a leading cause of global burden of disease, such behaviour on the part of doctors shows ignorance of patients' needs and negligence of medical duties.' But it is not only failure of the attending physicians but failure of the medical profession itself. The junior doctor who took the history and examined the patient first, the consultant who reviewed the patient, the nurses who took her vitals and showed her to the examination room and last but not least myself as a medical student who failed to bring up her obvious worries.
Psychiatric diseases often go untreated, not to speak of all those little ailments that have not made it into the latest Diagnostic and Statistical Manual of Mental Disorders which, however, still bother many of us. ${ }^{2-5}$ Taking a psychiatric history outside a psychiatric ward or clinic feels to be much more intrusive than any physical examination. It is something people want to speak about only behind closed doors. We - that includes both already practising doctors and medical students - often feel embarrassed by the mere thought of asking our patients about some "strange" thoughts, ticks and emotions. Are we trying to conceal our own inner turmoil?

In our society crazy is not cool. It is stupid. It is antisocial. It is dangerous. It is something we laugh about and something we definitely do not want to be. 6,7 When I wander through the corridors of any hospital I usually pick up easily many anecdotes, rumours and jokes made at the expense of everybody with a mental health problem. I frequently catch myself drifting into the same discriminatory pattern of thinking many doctors and fellow students have. Stigmatisation seems to be omnipresent and contagious. I often sense that making some negative comments on people with mental health problems is thought to be good form on the wards. However, such behaviour of medical staff can only discourage patients with mental health problems to seek professional help and we have to ask ourselves if denying help to some of society's most fragile members is what we want. ${ }^{7.8}$ I only wrote about Jane, but beware that John is her brother and though mental disorders are still commonly regarded as a "women's thing", he might also be troubled. ${ }^{9}$ 


\section{References}

1. Ferrari AJ, Charlson FJ, Norman RE, Patten SB, Freedman G, Murray CJ, et al. Burden of depressive disorders by country, sex, age, and year: findings from the global burden of disease study 2010. PLoS Med. 2013 Nov;10(11):e1001547.

2. American Psychiatric Association. Diagnostic and statistical manual of mental disorders. 5th ed. Arlington (VA): American Psychiatric Publishing; 2013.

3. Substance Abuse and Mental Health Services Administration. Results from the 2012 National Survey on Drug Use and Health: Mental Health Findings. NSDUH Series H-47, HHS Publication No. (SMA) 13-4805. Rockville (MD): Substance Abuse and Mental Health Services Administration; 2013.

4. World Health Organization (WHO) Regional Office for Europe. RC63 fact sheet on mental health. Copenhagen: WHO Regional office for Europe; 2013. 5. Garralda ME, Kramer T. Child and adolescent mental health problems in

\section{primary care. APT. 2000;6:287-294.}

6. Alonso J, Buron A, Bruffaerts R, He Y, Posada-Villa J, Lepine J-PAssociation of perceived stigma and mood and anxiety disorders: results from the World Mental Health Surveys. Acta Psychiatr Scand, 2008;118:305-314.

7. Directorate-Ceneral for Employment, Social Affairs and Inclusion, European Commission, Directorate-General for Health and Consumers. Countering the stigmatisation and discrimination of people with mental health problems in Europe. Luxembourg: Publications Office of the European Union; 2010.

8. Wang PS, Aguilar-Gaxiola S, Alonso J, Angermeyer MC, Borges C, Bromet EJ, et al.. Use of mental health services for anxiety, mood, and substance disorders in 17 countries in the WHO world mental health surveys. Lancet. 2007 Sep 8;370(9590):841-50.

9. World Health Organization. Department of Mental Health and Substance Dependence. Women's Mental Health: An Evidence Based Review. Geneva: World Health Organization; 2000.

\section{Acknowledgments}

None.

Conflict of Interest Statement at Funding

The author has no funding, financial relationships or conflicts of interest to disclose.

Author Contributions

Write the manuscript: JK

Cite as:

Kremling J. The Silent Suffering of Jane Doe: Negligence of Mental Health Problems in Daily Practice. Int J Med Students. 2014 JulOct;2(3):138-9. 